\title{
A mass spectrometric study of secondary organic aerosols formed from the photooxidation of anthropogenic and biogenic precursors in a reaction chamber
}

\author{
M. R. Alfarra ${ }^{1,2}$, D. Paulsen ${ }^{1,}$, M. Gysel ${ }^{1,2}$, A. A. Garforth ${ }^{3}$, J. Dommen ${ }^{1}$, A. S. H. Prévôt ${ }^{1}$, D. R. Worsnop ${ }^{4}$, \\ U. Baltensperger ${ }^{1}$, and $\mathrm{H} . \mathrm{Coe}^{2}$ \\ ${ }^{1}$ Laboratory of Atmospheric Chemistry, Paul Scherrer Institut, 5232 Villigen PSI, Switzerland \\ ${ }^{2}$ School of Earth, Atmospheric and Environmental Sciences, Univ. of Manchester, P. O. Box 88, Manchester M60 1QD, UK \\ ${ }^{3}$ School of Chemical Engineering and Analytical Sciences, Univ. of Manchester, P. O. Box 88, Manchester M60 1QD, UK \\ ${ }^{4}$ Aerodyne Research Inc., 45 Manning Road, Billerica, MA 01821, USA \\ *now at: Division of Engineering and Applied Sciences, Harvard University, Cambridge, MA 02138, USA
}

Received: 20 April 2006 - Published in Atmos. Chem. Phys. Discuss.: 10 August 2006

Revised: 8 November 2006 - Accepted: 10 November 2006 - Published: 20 November 2006

\begin{abstract}
An Aerodyne Aerosol Mass Spectrometer (AMS) has been utilised to provide on-line measurements of the mass spectral signatures and mass size distributions of the oxidation products resulting from irradiating 1,3,5trimethylbenzene (1,3,5-TMB) and $\alpha$-pinene, separately, in the presence of nitrogen oxide, nitrogen dioxide and propene in a reaction chamber. Mass spectral results indicate that both precursors produce SOA with broadly similar chemical functionality of a highly oxidised nature. However, significant differences occur in the minor mass spectral fragments for the SOA in the two reaction systems, indicating that they have different molecular composition. Nitrogencontaining organic compounds have been observed in the photooxidation products of both precursors, and their formation appeared to be controlled by the temporal variability of $\mathrm{NO}_{\mathrm{x}}$. Although the overall fragmentation patterns of the photooxidation products in both systems did not change substantially over the duration of each experiment, the contribution of some individual mass fragments to total mass appeared to be influenced by the irradiation time. The effective densities of the 1,3,5-TMB and $\alpha$-pinene SOA particles were determined for various particle sizes using the relationship between mobility and vacuum aerodynamic diameters. The effective density for the 1,3,5-TMB SOA ranged from $1.35-1.40 \mathrm{~g} / \mathrm{cm}^{3}$, while that for $\alpha$-pinene SOA ranged from $1.29-1.32 \mathrm{~g} / \mathrm{cm}^{3}$. The determined effective densities did not show dependence on irradiation time. Results suggest that further chemical processing of SOA takes place in
\end{abstract}

Correspondence to: M. R. Alfarra

(rami.alfarra@psi.ch) the real atmosphere, as neither the $\alpha$-pinene nor the $1,3,5$ TMB experimental results reproduce the right relative product distribution between carbonyl-containing and multifunctional carboxylic acid species measured at ambient locations influenced by aged continental organic aerosols.

\section{Introduction}

Understanding the formation, composition and behaviour of ambient aerosol particles is of critical importance due to their contribution to many important atmospheric processes, such as cloud formation (Novakov and Penner, 1993; Cruz and Pandis, 1997; Facchini et al., 1999a, b), visibility reduction (Macias et al., 1981; Vasconcelos et al., 1994) and direct radiative forcing (Charlson et al., 1992). Also, results of epidemiological studies indicate that exposure to ambient aerosol particles with aerodynamic diameters less than $2.5 \mu \mathrm{m}$ is correlated with daily mortality and morbidity rates (Dockery et al., 1993). However, to date, the climatic impact of aerosol particles is poorly quantified, and the compounds that contribute to adverse health effects have not been established. This is partly due to the fact that the chemical composition of ambient aerosol particles has not been fully characterised, in particular its organic fraction. While organic aerosol particles can be directly emitted into the atmosphere (e.g. biomass burning, combustion processes), they can also be introduced by secondary organic aerosol (SOA) formation. SOA formation occurs when volatile organic compounds undergo atmospheric oxidation reactions, forming products that have low enough volatilities

Published by Copernicus GmbH on behalf of the European Geosciences Union. 
to form aerosol via either nucleation or gas-to-particle partitioning to pre-existing particles (Odum et al., 1996; Hoffmann et al., 1997; Kamens et al., 1999; Kamens and Jaoui, 2001). Volatile organic compounds (VOCs) are emitted into the atmosphere from anthropogenic and biogenic sources (Went, 1960; Odum et al., 1996; Seinfeld and Pandis, 1998; Kleindienst et al., 1999; Aschmann et al., 2002). Anthropogenic VOC sources comprise organics such as alkanes, alkenes, aromatics and carbonyls, while biogenic sources include organics such as isoprene, monoterpenes and sesquiterpenes. Aromatics as well as monoterpenes are particularly important constituents of urban and regional atmospheric chemistry and most have been identified as SOA precursors (Odum et al., 1996; Griffin et al., 1999; Kamens et al., 1999; Larsen et al., 2001).

In situ investigation of key physical and chemical processes during SOA formation in the atmosphere is complicated by the vast number of species involved and their generally low concentrations. Hence reaction chambers are often used to study these processes. A reaction chamber is a large confined volume in which sunlight or simulated sunlight is used to irradiate mixtures of atmospheric trace gases (hydrocarbons, nitrogen oxides, sulphur dioxide, etc.) in purified air. Reaction chambers can be used to produce controlled atmospheres to investigate a range of physical phenomena from the formation of gas-phase reaction products to the partitioning of semi-volatile compounds between the gas and particle phase. Such experiments can be useful in understanding the chemical and physical parameters that control the formation of secondary organic aerosols. A number of reaction chamber studies have investigated gas-particle partitioning of products of photochemical reactions involving anthropogenic as well as biogenic precursors. Much of the efforts have been made to quantify the aerosol formation potential (aerosol yield) of small aromatic and natural hydrocarbon compounds both in the absence and presence of seed aerosol particles (Odum et al., 1996, 1997; Griffin et al., 1999; Kleindienst et al., 1999; Aschmann et al., 2002). Other studies have attempted to identify the molecular composition of the oxidation products of anthropogenic and biogenic precursors, mainly aromatic and monoterpene compounds, and have offered detailed reaction mechanisms for the formation of various chemical species (Forstner et al., 1997; Glasius et al., 2000; Jang and Kamens, 2001; Larsen et al., 2001; Griffin et al., 2002; Jaoui and Kamens, 2003; Kleindienst et al., 2004). In most of the studies, aerosol particles were collected on filters, extracted with solvents and then analysed off-line, using gas chromatography-mass spectrometry (GC-MS). Only $10-30 \%$ of the mass collected and extracted could be identified on a molecular level (Forstner et al., 1997; Cocker et al., 2001). More recently, online aerosol mass spectrometers have been employed to characterise SOA particles formed from photooxidation or ozonolysis experiments in smog chambers (Bahreini et al., 2005; Liggio et al., 2005; Gross et al., 2006).
Recent studies have reported that polymers and oligomers compose significant fractions of SOA formed from the photooxidation of aromatic and biogenic compounds (Gao et al., 2004a, b; Iinuma et al., 2004; Tolocka et al., 2004). Kalberer et al. (2004) found that about $50 \%$ of the SOA mass, formed from the photooxidation of 1,3,5-trimethylbenzene $(1,3,5-\mathrm{TMB})$ in a reaction chamber, consists of oligomers with molecular masses of up to 1000 daltons. Moreover, the formation of oligomeric molecules has been reported as an important step in the SOA production by the reaction of $\alpha$-pinene and ozone in the presence of acid seed aerosol (Tolocka et al., 2004). The study reported here follows on from Kalberer et al. (2004) and Baltensperger et al. (2005) and employs an Aerodyne aerosol mass spectrometer (AMS) to provide on-line measurements of the mass spectral signatures and mass size distributions of the oxidation products resulting from irradiating 1,3,5-TMB (anthropogenic precursor) and $\alpha$-pinene (biogenic precursor), separately, in the presence of nitrogen oxide, nitrogen dioxide and propene in a reaction chamber. Unlike most other studies, the objective is not to provide detailed chemical speciation of the photooxidation products of both precursors. This is due to the fact that the AMS does not utilise any means of chemical separation prior to the vaporisation and ionisation of the particles (Jayne et al., 2000; Jimenez et al., 2003b). Rather, this paper aims to study the change in the highly time resolved chemical signatures of the products from each precursor as a function of irradiation time, and to compare the chemical signatures and the densities of the SOA formed from these two precursors. In addition, the study attempts to investigate the extent of oxidation and oligomerisation of the aerosolphase reaction products. Finally, the implications of the photooxidation reactions carried out in this study on atmospheric measurements are discussed by comparing the mass spectral signatures of the products of both precursors to mass spectra of ambient organic particulate measured in relevant environments. Aerosol particles have been directly sampled from the reaction chamber into the AMS, avoiding any artifacts (e.g. evaporation, adsorption, filter contamination) usually associated with the off-line analysis methods.

\section{Experimental}

\subsection{Reaction chamber}

Experiments were carried out in the indoor reaction chamber at Paul Scherrer Institute (PSI). The PSI reaction chamber is a $27 \mathrm{~m}^{3}$ transparent Teflon ${ }^{\circledR}$ bag suspended in a temperaturecontrolled housing. The radiation was generated by four xenon arc lamps ( $4 \mathrm{~kW}$ each) selected to simulate the solar light spectrum and natural photochemistry. The construction of the facility and its operation are described in more detail elsewhere (Paulsen et al., 2005). 


\subsection{Instrumentation}

An Aerodyne aerosol mass spectrometer (AMS) was used to provide on-line quantitative measurements of the chemical composition and mass size distributions of the nonrefractory fraction of aerosol particles at a temporal resolution of two minutes. Detailed descriptions of the AMS measurement principles and various calibrations (Jayne et al., 2000; Jimenez et al., 2003b), its modes of operation (Jimenez et al., 2003b) and data processing and analysis (Allan et al., 2003a, 2004; Alfarra et al., 2004) are available in recent publications. In brief, the instrument utilises an aerodynamic lens (Liu et al., 1995a, b; Zhang et al., 2002, 2004) to produce a collimated particle beam that impacts on a porous tungsten surface heated typically to $550^{\circ} \mathrm{C}$ under high vacuum $\left(\sim 10^{-8}\right.$ Torr $)$, causing the non-refractory fraction of the particles to flash vaporise. The vapour plume is immediately ionised using a $70 \mathrm{eV}$ electron impact (EI) ionisation source, and a quadrupole mass spectrometer (QMA 410, Balzers, Liechtenstein) is used to analyse the resultant ions with unit mass-to-charge $(\mathrm{m} / \mathrm{z})$ resolution. A beam width probe (BWP) was used during these experiments to infer non sphericity of the particles through divergence of the particle beam arising from increases in the lift forces on the particles. The BWP and its application have been described in detail by Huffman et al. (2005).

Total particle number concentration (diameter $D_{p}>3 \mathrm{~nm}$ ) was monitored with a condensation particle counter (CPC, TSI model 3025). A scanning mobility particle sizer (SMPS) consisting of a differential mobility analyser (DMA, TSI model 3071) and a condensation particle counter (CPC, TSI model 3022) was used to measure particle size distributions from 7 to $316 \mathrm{~nm}$. A volatility tandem differential mobility analyser (VTDMA) was used to measure the volatile fraction of size-selected particles as described in previous publication (Kalberer et al., 2004; Paulsen et al., 2006). The following gas phase components were also measured: $\mathrm{CO}$ (AeroLaser AL5002), NO and $\mathrm{NO}_{\mathrm{x}}$ (ML 9841A and Thermo Environmental Instruments $42 \mathrm{C}$ retrofitted with a photolytic converter), $\mathrm{O}_{3}$ (UV-photometer: Environics S300), the precursor hydrocarbons and their oxidation products with a proton transfer reaction - mass spectrometer (PTR-MS, Ionicon). This paper primarily reports the AMS results, while most of the other measurements are discussed in separate publications (Paulsen et al., 2005, 2006).

\subsection{Experimental conditions}

Three experiments were carried out in the reaction chamber using each of the precursors, two of which were at "high" concentration and one was at "low" concentration. Table 1 summarises the initial conditions for each experiment. The "high" concentration levels were chosen to provide good signal statistics for the AMS, whereas the low concentration levels were chosen to be as close as possible to atmospherically relevant concentrations, while taking into account instrument detection limits. The chamber was purged with purified air for at least $24 \mathrm{~h}$ before each experiment. Primary gas components including precursor, nitrogen oxides, purified air and water vapour were introduced into the chamber where they were allowed to mix for approximately $45 \mathrm{~min}$ before the lights were turned on. Precursors were irradiated in the presence of $\mathrm{NO}_{\mathrm{x}}$ and propene at nominally $50 \%$ relative humidity for durations between 8 and $20 \mathrm{~h}$. $\mathrm{NO}_{\mathrm{x}}$ were added primarily to facilitate the basic photochemical cycle involving $\mathrm{O}_{3}(\mathrm{Se}-$ infeld and Pandis, 1998; Griffin et al., 1999; Finlayson-Pitts and Pitts, 2000), while propene was used as a photochemical initiator to provide $\mathrm{OH}$ radicals at sufficient levels for the inception of the experiment (Odum et al., 1996; Forstner et al., 1997; Griffin et al., 1999; Kleindienst et al., 1999).

\section{Overview of secondary organic aerosol (SOA) forma- tion}

It is predicted from the traditional theory of SOA formation that the non-volatile and semivolatile products from a photochemical reaction of an organic precursor accumulate with ongoing irradiation and when their gas phase saturation concentrations are exceeded, they begin to condense on pre-existing particles or, in the absence of seed aerosol particles, form new particles by homogeneous nucleation. The amount of a product that partitions into the particle phase is the quantity in excess of its gas phase saturation concentration (Odum et al., 1996). However, Pankow (1994a, b) suggested that, once organics begin to condense and an organic layer forms on the particles, even products whose gas phase concentrations are below their saturation concentrations will partition a portion of their mass into this condensed organic phase. Nucleation, condensation and subsequent adsorption and absorption of oxidation products lead to particles that are almost completely organic in composition. The quantity of aerosol produced in this case, estimated from the final aerosol volume after accounting for wall losses, provides a measure of the SOA formation potential in a clean environment.

A representative time profile of the particles evolution during a "high" concentration 1,3,5-TMB experiment (experiment number 3, Table 1) is illustrated in Fig. 1. The total particle number concentration $\left(\mathrm{cm}^{-3}\right)$ counted by the $\mathrm{CPC}$, is shown in the top panel, the nitrate-equivalent total mass loading $\left(\mu \mathrm{g} \mathrm{m}^{-3}\right)$ measured by the AMS (Jimenez et al., 2003b) is presented in the middle panel and the bottom panel shows particle mass size distribution measured as a function of its vacuum aerodynamic diameter. The latter has been defined elsewhere (Jimenez et al., 2003a; DeCarlo et al., 2004). The brief gaps in the data are periods where zero particle filter samples and/or particle density measurements were made. In general, the shapes of the time dependent number concentration and mass loading curves as well as particle mass size 
Table 1. Summary of conditions at the start of each experiment.

\begin{tabular}{cccccc}
\hline Experiment & Precursor & Concentration (ppbv) & $\mathrm{NO}(\mathrm{ppbv})$ & $\mathrm{NO}_{2}(\mathrm{ppbv})$ & Propene (ppbv) \\
\hline 1 & $1,3,5-\mathrm{TMB}$ & 35 & 11 & 8 & 300 \\
2 & $1,3,5-\mathrm{TMB}$ & 620 & 150 & 150 & 300 \\
3 & $1,3,5-\mathrm{TMB}$ & 620 & 150 & 150 & 300 \\
4 & $\alpha-$ Pinene & 160 & 94 & 77 & 300 \\
5 & $\alpha-$ Pinene & 30 & 55 & 68 & 300 \\
6 & $\alpha-$ Pinene & 160 & 59 & 67 & 300 \\
\hline
\end{tabular}

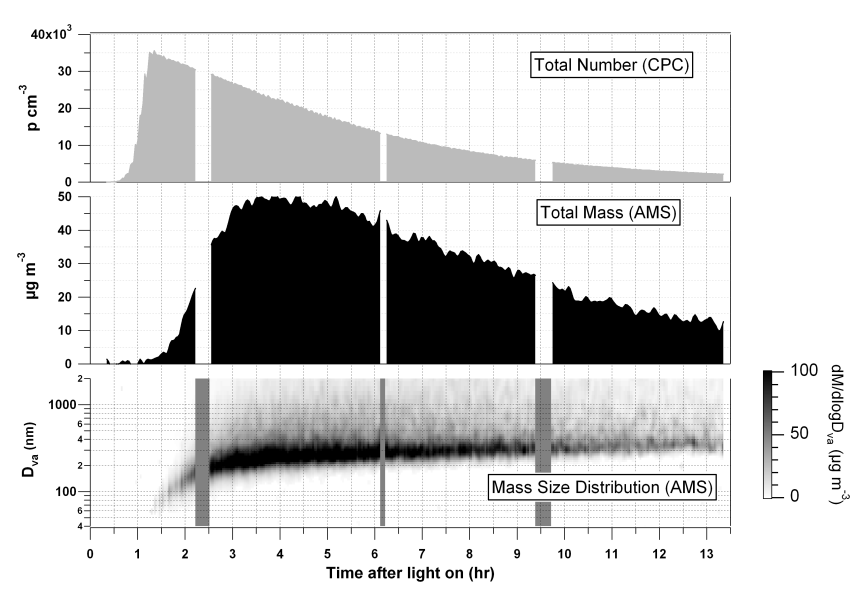

Fig. 1. Time profile of the evolution of particles during a "high" concentration 1,3,5-TMB experiment (experiment number 3, Table 1), showing the total particle number concentration $\left(\mathrm{cm}^{-3}\right)$ counted by the CPC in the top panel, the total nitrate-equivalent mass loading $\left(\mu \mathrm{g} \mathrm{m}^{-3}\right)$ measured by the AMS in the middle panel and particle mass size distribution measured as a function of its vacuum aerodynamic diameter in the bottom panel. Note that data is not corrected for wall losses. The tail off in mass loading at the high sizes above the main mode is not due to large particles, but results from high particle loads slowing the normally near instantaneous vaporisation of particles.

distributions were similar for all experiments, though their absolute values depended on the organic precursor and its initial concentration.

Each experiment began with a nucleation event marked by the increasing number concentration of particles, which then grew by condensation and coagulation as reflected in the increasing particle diameters. CPC data for the experiment in Fig. 1 show that particles grew to detectable sizes $(>3 \mathrm{~nm})$ about half an hour after the lights were turned on and their number concentration increased rapidly to peak at about $35000 \mathrm{~cm}^{-3}$ within another $40 \mathrm{~min}$. During experiment number 3 , the total mass loading of particles increased with ongoing particle formation and condensational growth and reached its maximum $3 \mathrm{~h}$ and $25 \mathrm{~min}$ after the start of irradiation, and then started to decrease gradually due to the dominance of particle wall losses. Aerosol mass concen- trations can be corrected for wall losses based on the observed decay of the particle number concentration, when particle formation has ceased to take place. This is particularly important for particle and product yield studies, where the quantity of aerosol produced in a clean environment is estimated from the final aerosol volume. However, this is not the focus of this paper and therefore, data were not corrected for wall losses. The delay between particle detection by the $\mathrm{CPC}$ and the AMS is due to the difference in particle size detection limit of both instruments $(3 \mathrm{~nm}$ for the CPC and about $40 \mathrm{~nm}$ for the AMS). As a result the AMS could only provide information on the particle growth and not nucleation, since the smallest particles that the AMS could analyse had about a thousand times more mass than the initial nuclei (Zhang et al., 2004). Gas phase measurements showed that ozone levels were below $1 \mathrm{ppb}$ at the beginning of each experiment and increased slowly as $\mathrm{NO}$ was converted to $\mathrm{NO}_{2}$, and then increased rapidly and peaked at about $300 \mathrm{ppb}$ as the NO mixing ratio decreased to values below $1 \mathrm{ppb}$. The gas phase data are discussed in more detail in separate publications (Kalberer et al., 2004; Paulsen et al., 2005).

\section{Chemical signatures}

One of the main objectives of this paper is to investigate the change of the chemical signature (also referred to as the mass spectral signature) of the photooxidation products of both precursors as a function of irradiation time. This will be first discussed for the products of each precursor followed by a comparison of their signatures at similar time intervals. The two "high" concentration experiments for 1,3,5-TMB (experiments 2 and 3, Table 1) resulted in similar SOA concentrations and reproducible mass spectra $(R=1.00$ for comparison of the averaged mass spectra for the two experiments). This was also true for the two "high" concentration experiments for $\alpha$-pinene (experiments 4 and 6, Table 1), which also showed an $\mathrm{R}$ value of 1.00 for the averaged spectra. On the other hand, low signal to noise levels in the 'low' concentration 1,3,5-TMB and $\alpha$-pinene cases (experiments 1 and 5 , respectively, Table 1) did not allow a useful comparison with the "high" concentration experiments. As a result, it is important to note that all spectra discussed in this paper for 
the photooxidation products of 1,3,5-TMB and $\alpha$-pinene are from the "high" concentration experiments 3 and 4, respectively, in Table 1. It is also worth noting that the reported chemical signatures are for the growing $(>40 \mathrm{~nm})$, not nucleating, particles in each case. Figure 2 shows mass spectra of the aerosol-phase photooxidation products of 1,3,5-TMB (panels a-c) and $\alpha$-pinene (panels $\mathrm{d}-\mathrm{f}$ ) averaged for one hour each after 3,5 and $8 \mathrm{~h}$ of irradiation (for example, the spectrum after $3 \mathrm{~h}$ is an average from the start of hour 2 to the start of hour 3). All spectra are normalised to the sum total of all mass fragments, providing a quantitative fractional contribution of each mass fragment to the total measured signal.

4.1 Discussion of the chemical signatures of the photooxidation products of 1,3,5-TMB and $\alpha$-pinene

The mass spectra of the photooxidation products of both $1,3,5-\mathrm{TMB}$ and $\alpha$-pinene are characterised by a very intense mass fragment at $m / z 43$, contributing about 18 and $13 \%$, respectively, to the total produced signal in each case. This fragment arises, typically, from either saturated hydrocarbons in the form of $\left(\mathrm{C}_{3} \mathrm{H}_{7}^{+}\right)$, or from oxidised, carbonylcontaining compounds (e.g. aldehydes and ketones) in the form of $\left(\mathrm{CH}_{3} \mathrm{CO}^{+}\right)$, which is more likely to be the case in this study. It was suspected that a possible reason for the domination of mass fragment 43 in both mass spectra was the use of propene in all experiments as a source of radicals. The photooxidation of propene is known to produce compounds like acetaldehyde and acetic acid, which produce mass fragment 43 as one of their main fragments upon ionisation by a $70 \mathrm{eV}$ EI source (McLafferty and Turecek, 1993). However, further experiments were conducted in the absence of propene where $m / z 43$ remained the most dominant fragment in the spectra.

Mass fragment 44 corresponds to the $\mathrm{CO}_{2}^{+}$fragment and laboratory experiments have shown that it arises, along with at least a similar amount of mass fragment $18\left(\mathrm{H}_{2} \mathrm{O}^{+}\right)$, from decarboxylation of oxo- and di-carboxylic acids (Alfarra, 2004), as well as highly oxidised compounds such as fulvic acid, which represents an example of humic-like substances. In many cases however, the mass fragment 18 also contains large contributions from gas phase water and gaseous organic molecules as well as from particulate water. To retrieve the total organic mass loading, the contribution of water resulting from decarboxylation at $m / z 18$ is set equal to $m / z 44$ based on laboratory results with pure compounds performed in argon, where the interferences to $m / z 18$ are eliminated (Aerodyne Research Inc., unpublished laboratory results). As a result, there is no independent information about the mass spectral signature of the observed organic in these experiments at $m / z 18$. The two fragments together contribute up to at least 12 and $16 \%$ to the total signal that is produced from the aerosol products of 1,3,5-TMB and $\alpha$-pinene, respectively. The contributions of $m / z 43$ and 44 indicate that the particles produced from the photooxidation of both

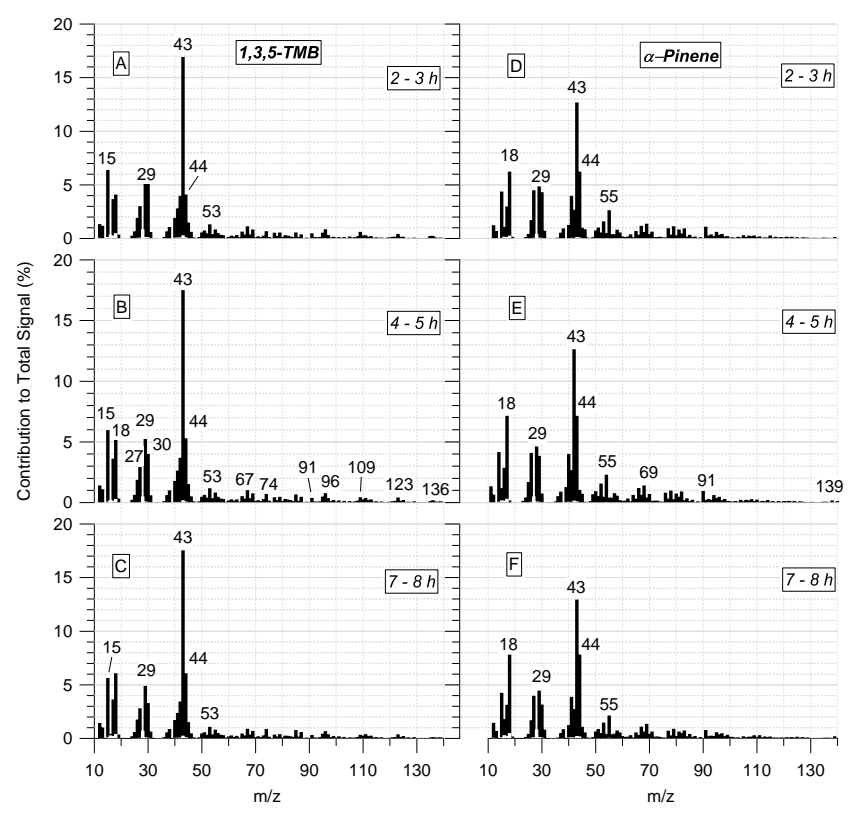

Fig. 2. Mass spectra of the photooxidation products of 1,3,5-TMB and $\alpha$-pinene (experiments 3 and 4 , respectively, Table 1) averaged for one hour each after 3,5 and $8 \mathrm{~h}$ of irradiation. All spectra are normalised to the sum total of all mass fragments, providing a quantitative fractional contribution of each mass fragment to the total measured signal. The white bars at the bottom of individual mass fragments are the associated errors as described by Allan et al. (2003a).

precursors are highly oxidised in nature and are dominated by carbonyl-containing and multifunctional carboxylic acid species. This is in agreement with previous reaction chamber studies, where highly oxidised chemical classes including di-, keto-, and hydroxy-keto- carboxylic acids in addition to ketones, keto-aldehydes, hydroxy-keto-aldehydes and hydroxy-ketones have been reported, in different concentrations and distribution patterns, as photooxidation products of aromatic and monoterpene compounds (Forstner et al., 1997; Glasius et al., 2000; Jang and Kamens, 2001; Larsen et al., 2001; Jaoui and Kamens, 2003; Kleindienst et al., 2004).

Mass fragments 15, 27 and 29 are signatures of the short carbon chains $\mathrm{CH}_{3}^{+}, \mathrm{C}_{2} \mathrm{H}_{3}^{+}$and $\mathrm{C}_{2} \mathrm{H}_{5}^{+}$, respectively, which most likely form part of the carbon structure of the oxidised compounds discussed above. They contribute a total of about 14 and $13 \%$ to the total produced signal from the products of $1,3,5$-TMB and $\alpha$-pinene, respectively. In addition, $m / z 29$ is likely to have contributions from the $\mathrm{HCO}^{+}$fragment arising from carbonyl-containing compounds.

A large number of low-intensity fragments account for the rest of the produced signal. These fragments typically contribute less than $3 \%$ each to the total produced signal from each precursor, but are clearly observable above the background. Figure 3 displays the mass spectra shown in panels (a) and (d) in Fig. 2 on a logarithmic scale in order to 

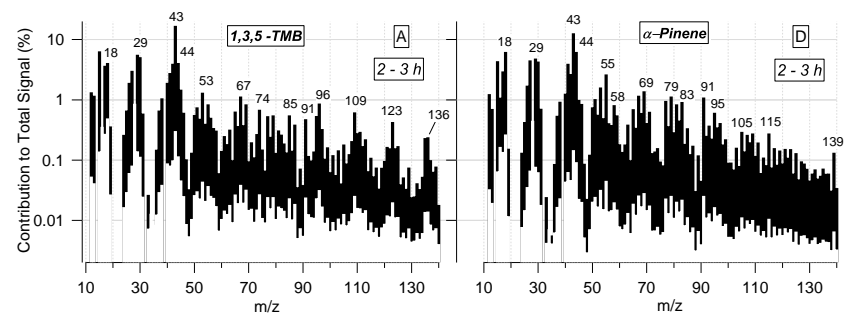

Fig. 3. A logarithmic scale presentation of the mass spectra shown in panels (a) and (d) in Fig. 2 in order to better illustrate the distribution patterns of the low-intensity mass fragments produced from the photooxidation of 1,3,5-TMB and $\alpha$-pinene. The white bars at the bottom of individual mass fragments are the associated errors as described by Allan et al. (2003a).

better illustrate the distribution patterns of the low-intensity mass fragments in each case. The relatively low contributions of these fragments to total signal do not, necessarily, indicate that they are insignificant in terms of their chemical signature. It is likely that many of their parent molecules are thermally unstable at the vaporisation temperature of the AMS $\left(550^{\circ} \mathrm{C}\right)$, and they are readily converted into smaller forms before being ionised. This may, as a result, enhance the intensity of the small fragments. However, this does not rule out a second possibility, whereby the photooxidation products yield these low mass fragments directly as major ionisation products.

\subsection{Chemical signatures as a function of irradiation time}

The time resolved mass spectra of the 1,3,5-TMB products (panels a-c in Fig. 2) appear to have highly similar fragmentation patterns, implying that the chemical signature of the products does not markedly change overall with irradiation time. This is also true for mass spectra of the $\alpha$-pinene products (panels $d-f$ in Fig. 2). This finding was further examined through a detailed inspection of hourly averaged mass spectra throughout the duration of each experiment (not shown in Fig. 2). In order to quantify these similarities, the hourly averaged mass spectra from Fig. 2 measured at 5 and $8 \mathrm{~h}$ were compared to those measured at $3 \mathrm{~h}$ of irradiation time for each precursor. Pearson's $r$ values of 0.99 and 0.98 for the 1,3,5-TMB comparisons and 1.00 and 0.99 for the $\alpha$-pinene case were found and are shown in Fig. 4, confirming that the chemical signature of the photooxidation products of each precursor after 5 and $8 \mathrm{~h}$ of irradiation time does not appear to significantly change from that after only $3 \mathrm{~h}$ of irradiation. This indicates that once particles are formed, it is unlikely that long periods of irradiation lead to a significant change in the particle chemical signature measured by the AMS under these conditions. However, evidence of oligomerisation has recently been reported under the same conditions, showing an increase in the particle non-volatile fraction as well as high molecular weight mass fragments $(m / z>400)$ as a

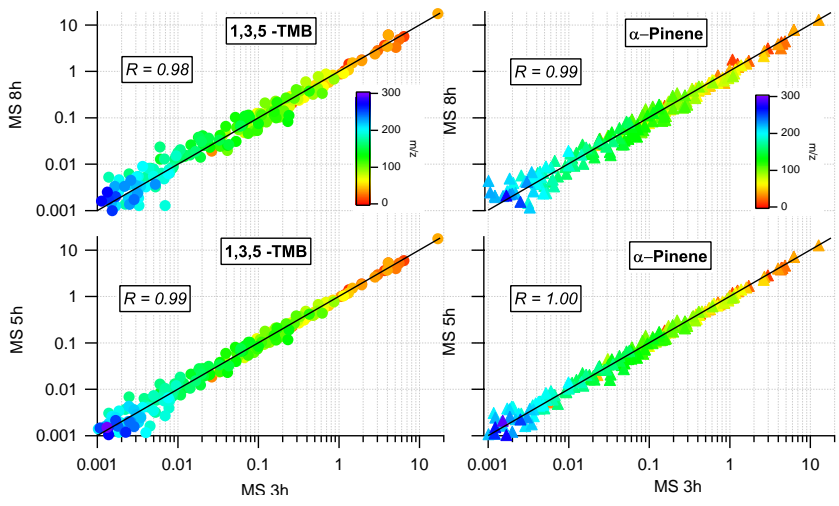

Fig. 4. Comparison of the fragmentation patterns of the photooxidation products of 1,3,5-TMB after 5 and $8 \mathrm{~h}$ with that after $3 \mathrm{~h}$ of irradiation (left panels). The plotted data are the fractional contributions of each mass fragment to total signal as shown in Fig. 2. The colour scale is a function of $\mathrm{m} / \mathrm{z}$ number and the black line is the slope of unit gradient. An identical comparison of the $\alpha$-pinene data is shown on the right panels.

function of irradiation time (Kalberer et al., 2004; Gross et al., 2006). On the other hand, the ratio of the volume concentration (measured by the SMPS) and the mass concentration (measured by the AMS) remained constant over the time of the experiment, even though the AMS only reports mass fragments up to $m / z 300$. Therefore it is likely that the large molecules break into fragments mainly below $m / z 200$ upon volatilisation and ionisation in the AMS.

Although the overall fragmentation patterns of the photooxidation products from both precursors did not change substantially over the duration of each experiment (i.e. the order of magnitude of the fractional contribution to the total mass by individual mass fragments after 5 and $8 \mathrm{~h}$ remained as it was after $3 \mathrm{~h}$ of irradiation), the contribution of some individual mass fragments to total mass appeared to be influenced by the irradiation time. The effect of irradiation time on the fractional contribution of individual mass fragments to the total mass after 5 and $8 \mathrm{~h}$ relative to that after $3 \mathrm{~h}$ of irradiation is shown in Fig. 5 for both precursors, and was calculated for the mass spectra shown in Fig. 2 by comparing the percentage change, $D$, of each mass fragment at 5 and $8 \mathrm{~h}$ compared to that observed at $3 \mathrm{~h}$ using the following expression:

$D(\%)=\left(\frac{\mathrm{MS}_{i \mathrm{~h}}-\mathrm{MS}_{3 \mathrm{~h}}}{\mathrm{MS}_{3 \mathrm{~h}}}\right) \cdot 100$

Where $\mathrm{MS}_{i \mathrm{~h}}$ refers to the mass spectra after 5 and $8 \mathrm{~h}$ and $\mathrm{MS}_{3 \mathrm{~h}}$ to the mass spectra after $3 \mathrm{~h}$ of irradiation in Fig. 2.

Figure 5 shows that the fractional contributions of some mass fragments to total signal increase with irradiation time. For example, the fractional contribution of $\mathrm{m} / z 44\left(\mathrm{CO}_{2}^{+}\right.$ from highly oxidised acidic compounds), appears to increase after $8 \mathrm{~h}$ of irradiation by about $50 \%$ and $25 \%$ relative to its 
contribution after $3 \mathrm{~h}$ of irradiation in the cases of 1,3,5-TMB and $\alpha$-pinene, respectively. These temporal changes are similar to the increases observed in the low volatile fraction of the aerosol measured by the VTDMA in these experiments and those reported by Kalberer et al. (2004). Interestingly, the fractional contributions of larger mass fragments, such as $\mathrm{m} / z 127,140$ and 155 in the 1,3,5-TMB case and $m / z 100$ and 156 in the $\alpha$-pinene case, appear to increase after $8 \mathrm{~h}$ of irradiation by as much as $100 \%$ and $75 \%$, respectively, indicating that the significance of larger mass fragments increases with irradiation time. Although the actual contributions of these mass fragments to total signal are very low, this could be indirect evidence for the formation of large molecules in both systems. On the other hand, Fig. 5 shows that the fractional contributions of other mass fragments to total signal appear to decrease with irradiation time. It is possible that these changes are due to either oxidation of the molecules in the aerosol over time, or other particle-phase reactions such as aldol condensation or other oligomerisation mechanisms.

4.3 Comparison of the chemical signatures of the photooxidation products of 1,3,5-TMB and $\alpha$-pinene

Another objective of this study is to compare the mass spectral signatures of the photooxidation products of a typical anthropogenic (1,3,5-TMB) and a biogenic ( $\alpha$-pinene) precursor. The mass spectra in Fig. 3 illustrate that the chemical signature of the products from both precursors, after equal periods of irradiation, are broadly similar. Both spectra are dominated by mass fragment 43 and, to a lesser extent, mass fragment 44 representing highly oxidised classes of compounds containing carbonyl and carboxylic acid functional groups.

Because of the extensive fragmentation caused by electron impact ionisation and the similarity in mass spectra of compounds in the same chemical classes, most mass fragments appear to be present in the mass spectra of the SOA produced from both precursors. A detailed study of the mass spectra in Figs. 2 and 3 shows, however, that differences do exist between both chemical signatures. For example, $m / z$ 43 contributes about $17 \%$ to the total signal produced from $1,3,5-\mathrm{TMB}$, while it contributes $13 \%$ in the $\alpha$-pinene case. On the other hand, mass fragments in the 50 to $100 \mathrm{~m} / z$ range appear to be more pronounced in the $\alpha$-pinene case. Another consistent difference is in the 53/55 and 67/69 mass fragment ratios, where the smaller mass fragment appears to be always higher in the 1,3,5-TMB spectra, while the opposite is true in the $\alpha$-pinene case. Furthermore, mass fragments 74, 96, 135,136 and the ion series 95, 109, 123 appear to be more strongly associated with 1,3,5-TMB, and mass fragments 58, $83,115,139,141,167$ and 199 with $\alpha$-pinene. More differences in the chemical composition of the SOA formed from both precursors can be drawn from Fig. 5. It shows that the mass fragments that have increasing fractional contribution

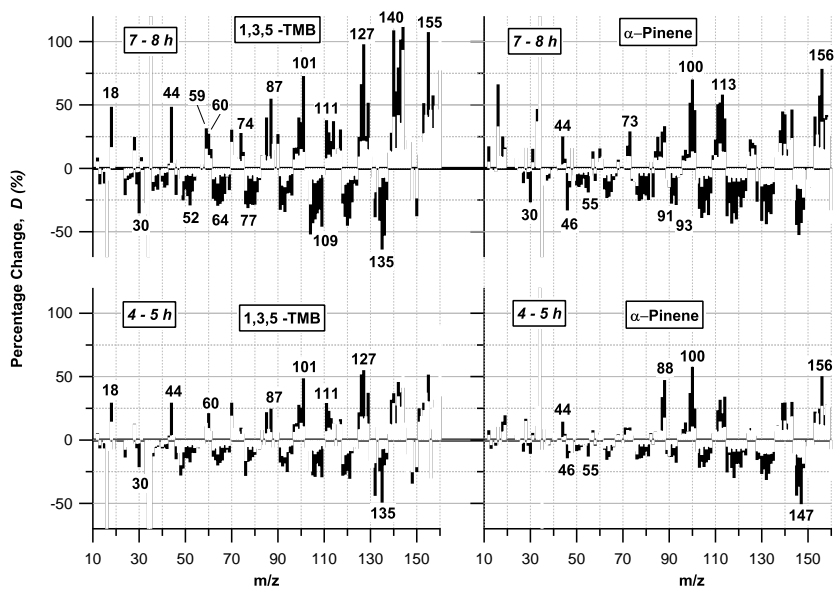

Fig. 5. The percentage change $(D)$ in the fractional contribution of individual mass fragments to total signal at 5 and $8 \mathrm{~h}$ compared to that observed at $3 \mathrm{~h}$ of irradiation for the photooxidation products of 1,3,5-TMB and $\alpha$-pinene calculated by Eq. (1). The white bars on the individual mass fragments are errors propagated through Eq. (1).

to total signal as a function of irradiation time are distinctly different for each precursor. These mass fragments include $59,74,87,101,127,140$ and 155 in the case of 1,3,5-TMB and 73,100, 113 and 156 in the $\alpha$-pinene case. Although it is not possible to exclusively relate the individual mass fragments to specific chemical compounds, the above observations indicate that the SOA produced from each precursor are likely to have broadly similar chemical functionality given by the high abundance of $m / z 43$ and 44 . However, significant differences occur in the minor fragments for the SOA in the two reaction systems, indicating that the precise molecular composition differs.

\section{Formation of nitrogenated organic compounds}

Mass fragments 30 and 46 observed with the AMS during atmospheric sampling have been mostly interpreted as $\mathrm{NO}^{+}$ and $\mathrm{NO}_{2}^{+}$from inorganic nitrate compounds (Allan et al., 2003b; Jimenez et al., 2003b; Boudries et al., 2004). In this study, both fragments were observed in the mass spectra of the photooxidation products of both precursors (Fig. 2). The temporal behaviour of both fragments was found to be very similar within each of the experiments. This similarity is quantified in Fig. 6, where concentrations of mass fragments 30 and 46 are correlated for each precursor. Both correlations have high Pearson's $r$ values of 0.98 and 0.92 for 1,3,5-TMB and $\alpha$-pinene, respectively. However, their temporal behaviour is significantly different from other major fragments observed. Once the $\mathrm{NO}_{\mathrm{x}}$ has been consumed the rate of change of these mass fragments is controlled by wall losses only. This is not the case for other mass fragments 


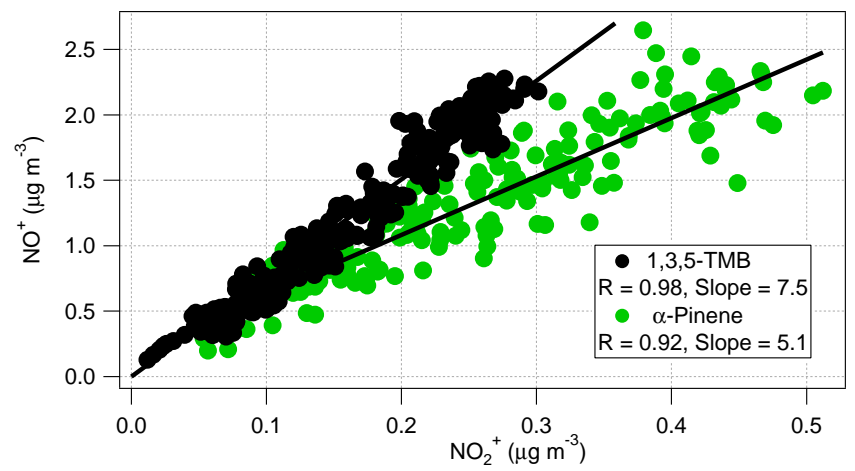

Fig. 6. Correlation of the nitrate-equivalent mass concentrations of mass fragments $30\left(\mathrm{NO}^{+}\right)$and $46\left(\mathrm{NO}_{2}^{+}\right)$produced from the photooxidation of $1,3,5-\mathrm{TMB}$ and $\alpha$-pinene.

such as $m / z$ 43. This indicates that, in each case, both fragments are likely to have the same chemical source.

Organic nitrates and nitro-compounds are possible candidates. Laboratory studies showed that for inorganic nitrate salts, the ratio of mass fragments 30 to 46 varies with the type of cation in each salt. For example, the 30/46 ratio is 2 to 3 for ammonium nitrate, 11 for magnesium nitrate and 29 for sodium nitrate. In this study, the $30 / 46$ ratio is 8 for the products of 1,3,5-TMB and 5 for the $\alpha$-pinene case. The ratio was constant over the duration of both experiments. The different values of the 30/46 ratios may imply that different nitrogenated compounds are formed from each precursor. The formation of nitro organic compounds has already been reported in a number of chamber studies. Forstner et al. (1997) presented a detailed mechanism leading to the formation of nitro aromatic compounds from the photooxidation of toluene in the presence of $\mathrm{NO}_{\mathrm{x}}$ and propene. Pathways for production of nitrophenolic compounds from an ethylbenzene- $\mathrm{OH}$ adduct were also discussed. In a similar recent study, Kleindienst et al. (2004) suggested that $\mathrm{NO}_{2}$ addition to aromatic rings becomes more significant at elevated concentrations of $\mathrm{NO}_{2}$, which is usually the case in environmental chamber studies. It was explained that the $\mathrm{NO}_{2}$ addition stabilises the ring intermediate leading to the formation of nitro and di-nitro aromatic compounds. In a third study of the same system, the contribution of alkyl nitrates $\left(\mathrm{RONO}_{2}\right)$ or peroxyacyl nitrates $\left(\mathrm{RC}(\mathrm{O}) \mathrm{OONO}_{2}\right)$ to the secondary organic aerosol formation was positively verified using FTIR spectroscopy (Jang and Kamens, 2001). In addition, many modelling and experimental studies have examined and reported the formation of nitrate compounds from the oxidation of $\alpha$-pinene and other terpenes (Aschmann et al., 1998, 2002; Noziere and Barnes, 1998; Noziere et al., 1999; Kamens and Jaoui, 2001). Mono- and di-alkyl nitrates, peroxyacetylnitrate (PAN) and PAN-related compounds were among the reported gaseous and particle phase products in a modeling study (Kamens and Jaoui, 2001; Jaoui and Kamens, 2003).

The time-resolved mass spectra in Fig. 2, as well as the time-varying relative fractional contributions of individual mass fragments to total mass in Fig. 5 show that the contributions of the mass fragments 30 and 46 to total signal decrease with time for both precursors. The contribution of the sum of $\mathrm{NO}^{+}$and $\mathrm{NO}_{2}^{+}$to the total signal starts as high as $7 \%$ and decreases to about $3 \%$ after about $8 \mathrm{~h}$ of irradiation. This is likely to be explained by the consumption of the gas phase $\mathrm{NO}_{\mathrm{x}}$ after only 3 and $5 \mathrm{~h}$ of the start of 1,3,5-TMB and $\alpha$-pinene experiments, respectively.

\section{Formation of oligomers in the absence of oxidation}

About 30 small carbonyls and acids have been recently measured in the gas and particle phase products of an identical 1,3,5-TMB photooxidation experiment to the one discussed in this study (Kalberer et al., 2004). GC-MS and ion chromatography (IC) were used to identify the oxidation products (Fisseha et al., 2004). Methylglyoxal, a $\mathrm{C}_{3}$-dicarbonyl, was found to be one of the most abundant gas-phase photooxidation products of 1,3,5-TMB (Calvert et al., 2002). Recent studies have suggested that additional partitioning of carbonyls to the particle phase may occur via chemical transformation of the carbonyls to low volatility products (Tobias and Ziemann, 2000; Jang et al., 2003; Gao et al., 2004a, b; Iinuma et al., 2004; Tolocka et al., 2004; Liggio et al., 2005; Kroll et al., 2005). The hydration of the carbonyl followed by acid-catalysed oligomerisation or acetal/hemiacetal formation in the presence of alcohol have been reported as a potential mechanism for this transformation (Jang et al., 2003).

An aqueous solution of glyoxal is composed of a mixture of hydrated monomers, dimers and trimers forming acetals (Kalberer et al., 2004, and references therein). Laser Desorption Ionisation Mass spectrometry (LDI-MS) measurements of methylglyoxal showed oligomers up to the nonamer with $m / z=723$. An LDI mass spectrum of an equal-mass aqueous solution of methylglyoxal, formaldehyde, 3,5-dimethylbenzaldehyde and pyruvic acid (all known "aerosol-phase" oxidation products of 1,3,5-TMB except formaldehyde, which is a "gas-phase" product) showed an oligomer pattern similar to that produced from the photooxidation products of 1,3,5-TMB in the range $400<m / z<900$ (Kalberer et al., 2004). On this basis, Kalberer et al. (2004) proposed a nonradical-induced acetal oligomerisation with methylglyoxal as the main monomer unit, with the possibility that other carbonyls and carbonyl-containing acids may also be incorporated into the oligomer. However, other oligomer formation mechanisms are also possible. The oligomer fraction was quantified using a volatility tandem differential analyser (VTDMA), which measures the size reduction of the aerosol due to evaporation in a heater that has tube wall temperatures of 100,150 , and $200^{\circ} \mathrm{C}$ (Paulsen et al., 2006). Measurements showed that the particle volume fraction remaining at $100^{\circ} \mathrm{C}$ gradually increased from about $30 \%$ to $85 \%$ over $27 \mathrm{~h}$ of irradiation (Kalberer et al., 2004). This in- 
crease in nonvolatile particle fraction was mostly attributed to oligomer formation. Similar measurement trends were reported at $150^{\circ} \mathrm{C}$ and $200^{\circ} \mathrm{C}$. The VTDMA results of $1,3,5-$ TMB photooxidation products were reproduced during the study presented in this paper and similar trends were also measured for the $\alpha$-pinene photooxidation products (Paulsen et al., 2006).

In order to further investigate the role of the oligomerisation and photooxidation processes in these experiments, organic particles were generated using solutions of methanol and methylglyoxal, particle-free pure air, and a collision atomiser (see Paulsen et al., 2006, for particle generation system description). The particles were delivered into a 200 litre, opaque, carbon-impregnated, polyethylene plastic bag, in the absence of $\mathrm{NO}_{\mathrm{x}}$, propene and irradiation. The AMS and the VTDMA were used to simultaneously measure the methylglyoxal particles over approximately $2 \mathrm{~h}$. The VTDMA results using a heater wall temperature of $100^{\circ} \mathrm{C}$ showed that the remaining non-volatile particle volume fraction increased from $38 \%$ to $46 \%$ over $1.5 \mathrm{~h}$, giving a rate of $4.7 \% \mathrm{~h}^{-1}$ (a rate of $4.3 \% \mathrm{~h}^{-1}$ was obtained for water and methylglyoxal, rates were determined from a linear leastsquares regression). A similar analysis of the linear portion of reaction chamber data (first $8 \mathrm{~h}$, data from Kalberer et al., 2004) for high and low concentration 1,3,5-TMB cases produced rates of $3.7 \% \mathrm{~h}^{-1}$ and $3.1 \% \mathrm{~h}^{-1}$, respectively. These similar rates demonstrate that photochemistry is not required for methylglyoxal to oligomerise. A similar VTDMA result revealed a slower oligomerisation rate of $2.6 \% \mathrm{~h}^{-1}$ when the same experiment was repeated using the four-compound mixture of methylglyoxal, formaldehyde, 3,5-dimethylbenzaldehyde and pyruvic acid reported in Kalberer et al. (2004).

Figure 7 shows the averaged mass spectra of the methylglyoxal particles (bottom panel) and the oligomerisation products formed by the mixture compounds (top panel) measured by the AMS. Although the molecular weight of methylglyoxal is 72 , its mass spectrum shows mass fragments up to $m / z$ 133. This observation supports findings of other studies regarding the presence of dimers and trimers in glyoxal solutions (Kalberer et al., 2004, and references therein). A detailed investigation of the mass spectra of methylglyoxal and the mixture at high time resolution showed no significant change in the chemical signature of any of them with time. This is likely because the oligomer shows the same fragmentation pattern in the AMS as the monomer molecules. A comparison of the mass spectral signatures in Fig. 7 to that of 1,3,5-TMB photooxidation products (Fig. 2, panel a) indicates some differences, such as the absence of many of the low intensity mass fragments in the spectra in Fig. 7. The compounds introduced into the bag are those proposed by Kalberer et al. (2004) as possible candidates for 1,3,5-TMB SOA formation. Whilst they do indeed lead to the formation of organic aerosol, the AMS fragmentation pattern observed is distinctly different from those measured from 1,3,5-TMB

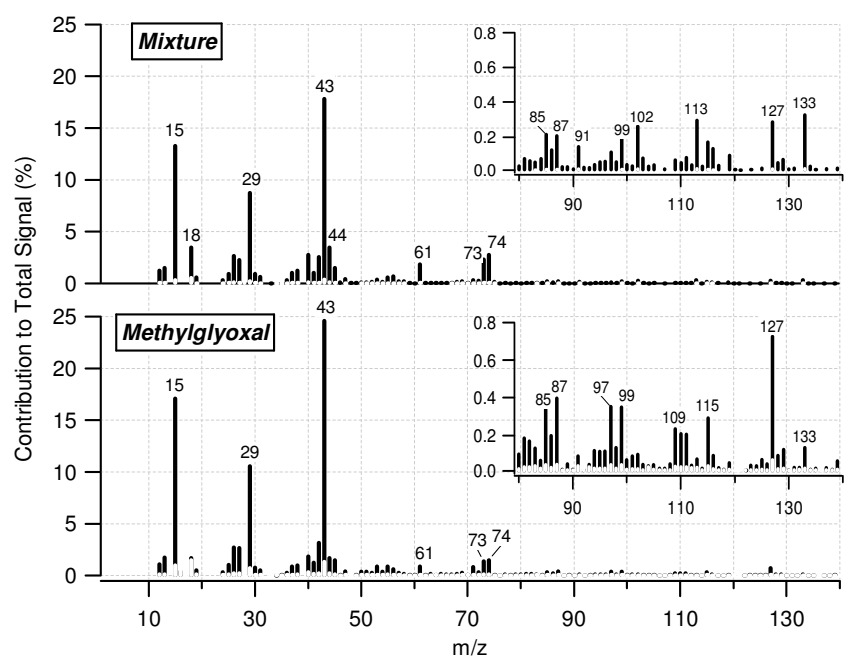

Fig. 7. Mass spectral signatures of the oligomers formed in the absence of oxidation by methylglyoxal, in the bottom panel, and the four compound mixture proposed by Kalberer et al. (2004), in the top panel.

Table 2. Effective densities for different selected particle sizes of $1,3,5$-TMB and $\alpha$-pinene SOA.

\begin{tabular}{ccc}
\hline & \multicolumn{2}{c}{$1,3,5-T M B$ SOA } \\
\hline $\mathrm{D}_{m}(\mathrm{~nm})$ & $\mathrm{D}_{v a}(\mathrm{~nm})$ & Effective Density $\left(\mathrm{g} / \mathrm{cm}^{3}\right)$ \\
\hline 140 & 193 & $1.38 \pm 0.10$ \\
210 & 291 & $1.39 \pm 0.10$ \\
230 & 310 & $1.35 \pm 0.10$ \\
270 & 367 & $1.36 \pm 0.10$ \\
290 & 397 & $1.37 \pm 0.10$ \\
300 & 419 & $1.40 \pm 0.10$ \\
\hline & & $\alpha$-Pinene SOA \\
\hline 190 & 251 & $1.32 \pm 0.10$ \\
250 & 328 & $1.29 \pm 0.09$ \\
270 & 348 & $1.31 \pm 0.10$ \\
280 & 367 & \\
290 & 374 &
\end{tabular}

oxidation in the chamber. This appears to be in line with the hypothesis of Kalberer et al. (2004) that additional photooxidation products (e.g. other carbonyls) take part in the oligomerisation process.

\section{Determination of SOA density}

The AMS provides a measure of the aerodynamic diameter of submicron particles in the free-molecular regime, which is known as the vacuum aerodynamic diameter $\left(D_{v a}\right)$ (Jimenez et al., 2003a). The use of a differential mobility analyser (DMA) and an AMS for parallel measurements of the mo- 


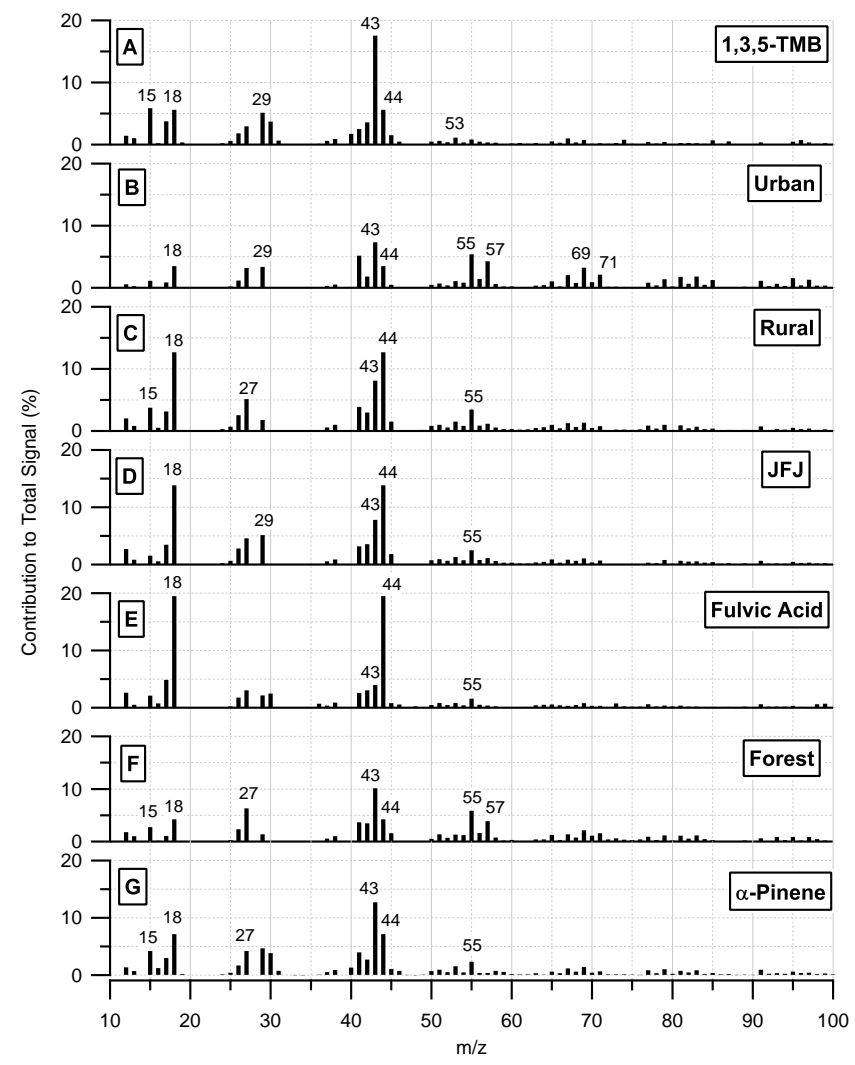

Fig. 8. A compilation of AMS mass spectral signatures of SOA produced from 1,3,5-TMB and $\alpha$-pinene from this study (a) and (g), laboratory generated fulvic acid particles (e) and organic particulate measured in the ambient atmosphere in urban (b) and rural (c) locations in British Columbia, Canada, the Jungfraujoch (JFJ) remote high-alpine location, Switzerland and a forest in Finland (f).

bility $\left(D_{m}\right)$ and vacuum aerodynamic diameters of aerosol particles have been reported to determine the effective density of aerosol particles (DeCarlo et al., 2004; Bahreini et al., 2005). The effective density is simply defined as the ratio of the vacuum aerodynamic to the mobility diameters (Jayne et al., 2000; DeCarlo et al., 2004) and it is equivalent to the density of a spherical particle but they can be significantly different when a particle is irregular in shape. The theory and the mathematical formulae for different particle shapes have been reported and discussed in detail by DeCarlo et al. (2004). In this study, a DMA was used to select 1,3,5-TMB and $\alpha$-pinene SOA particles of different individual sizes, which were then delivered, in series, into the AMS to measure their vacuum aerodynamic diameters. Table 2 lists all the selected particle mobility diameters, their measured vacuum aerodynamic diameters and the corresponding effective densities. The effective density for the 1,3,5-TMB SOA ranged from $1.35-1.40 \mathrm{~g} / \mathrm{cm}^{3}$, while that for $\alpha$-pinene SOA ranged from $1.29-1.32 \mathrm{~g} / \mathrm{cm}^{3}$. The results show that the effective density for both types of SOA is independent of particle size, implying that it does not significantly change with irradiation time for the experiments reported in this study.
Additional measurements were carried out using a beam width probe (BWP) in order to investigate the morphology of the SOA particles formed from both precursors. The results showed that both the 1,3,5-TMB and $\alpha$-pinene SOA produced a highly collimated and narrow aerosol particle beams. These results could be interpreted as indirect evidence that the SOA particles produced from both precursors were spherical in shape, and consequently the effective densities reported here are equivalent to the SOA densities.

\section{Atmospheric implications}

The lack of seed aerosol particles and the use of relatively high concentrations of precursors and $\mathrm{NO}_{\mathrm{x}}$ mean that particles produced during this study are not expected to have chemical signature identical to ambient particles. However, the irradiation of 1,3,5-TMB and $\alpha$-pinene in the presence of $\mathrm{NO}_{\mathrm{x}}$ and propene may simulate the ambient photooxidation process of aromatic and biogenic precursors, respectively. In Fig. 8, we present a compilation of mass spectra obtained from a number of AMS studies of the ambient atmosphere in various environments, along with the mass spectra of the photooxidation products of 1,3,5-TMB and $\alpha$-pinene from this study (panels a and g, respectively). The aim is to evaluate how the mass spectral signatures of the photooxidation products of 1,3,5-TMB and $\alpha$-pinene observed in this study compare to mass spectral signatures of the aerosol organic fraction measured in various environments affected to varying degrees by anthropogenic or biogenic precursors.

All spectra in Fig. 8 are averaged over the duration of each experiment and are normalised to show the fractional contribution of each mass fragment to the total organic signal. The spectra in panels (b) and (c) are of the aerosol organic fraction at urban (Slocan Park) and rural (Langley) locations, respectively, in the Lower Fraser Valley, British Columbia, Canada, and were measured as part of the $\mathrm{Pa}$ cific 2001 experiment (Alfarra et al., 2004; Boudries et al., 2004). Panel (d) shows a mass spectrum of the particulate organic fraction measured at the remote high-alpine location Jungfraujoch (JFJ), Switzerland, during the second Cloud and Aerosol Characterisation Experiment (CLACE2) in 2002 (Alfarra, 2004). The mass spectrum in panel (e) is from laboratory generated fulvic acid particles. Fulvic acid has been shown to be a good model compound to explain the chemical functionality of the water-soluble macromolecular group of "humic-like substances" (HULIS), which have recently been found to contribute $20-50 \%$ to the water-soluble fraction of organic aerosol at urban and rural sites, as well as fog samples in Europe (Havers et al., 1998; Facchini et al., 1999a; Zappoli et al., 1999; Decesari et al., 2000; Krivacsy et al., 2000,2001 ). The mass spectrum in panel (f) is from a particle growth period following a nucleation event at the forest research station at Hyytiälä in Finland during the second Quantification of Aerosol Nucleation in the European 
Table 3. Pearson's R values resulting from the correlations of the mass spectra in Fig. 8.

\begin{tabular}{lcccccc}
\hline & \multicolumn{2}{c}{$1,3,5$-TMB } & \multicolumn{2}{c}{$\alpha$-Pinene } & \multicolumn{2}{c}{ Fulvic Acid } \\
\hline & All $m / z$ 's & $m / z>45$ & All $m / z$ 's & $m / z>45$ & All $m / z$ 's & $m / z>45$ \\
\hline Urban & 0.71 & 0.67 & 0.80 & 0.82 & 0.50 & 0.73 \\
Rural & 0.75 & 0.78 & 0.87 & 0.95 & 0.93 & 0.88 \\
JFJ & 0.73 & 0.79 & 0.85 & 0.94 & 0.94 & 0.86 \\
Forest & 0.80 & 0.64 & 0.86 & 0.82 & 0.54 & 0.78 \\
\hline
\end{tabular}

Boundary Layer experiment (QUEST 2) in 2003 (Allan et al., 2006).

In order to quantify the comparisons of the mass spectral signatures shown in Fig. 8, the fractional contributions of the individual mass fragments to the total signal of the organic particulates measured at the ambient locations were scatter plotted against those of the 1,3,5-TMB SOA, $\alpha$-pinene SOA and fulvic acid and the resulting Pearson's R values are summarised in Table 3. The fact that two mass fragments ( $m / z 43$ and 44) mostly dominate the mass spectra in Fig. 8 may lead to a bias in the linear regression analysis reported here. For this reason, we have performed the analyses on the whole mass spectra $(m / z 10-300)$ and also on the mass fragments larger than $m / z 45$. Results show that the mass spectral signature of the humic-like substance (fulvic acid) is significantly more similar to the spectral signatures of the organic particulates measured at the rural and remote alpine sites than to those of the urban and freshly nucleated forest particles. This indicates that the major chemical functional groups of the organic aerosols at the rural and remote sites are closely represented by those of the humic-like substance. The results also reveal that the photooxidation products of $\alpha$ pinene have higher correlations than those of the 1,3,5-TMB with the organic particulates measured at the ambient locations. The photooxidation products of $\alpha$-pinene show even higher correlations with the rural and the remote alpine sites for the analysis performed on $\mathrm{m} / \mathrm{z}$ larger than 45 . The latter analysis suggests that with the exception of the relative distribution of mass fragments 43 and 44, the $\alpha$-pinene SOA is similar in composition to the ambient organic aerosols measured at those sites. This could be due to the reported higher aerosol formation potential of biogenic compounds compared to those from anthropogenic sources (Odum et al., 1996; Griffin et al., 1999) and to the fact they are emitted in much more significant amounts into the atmosphere. The total annual global emission of biogenic compounds has been estimated around $825 \mathrm{TgCyr}^{-1}$ (Fehsenfeld et al., 1992; Guenther et al., 1995), whereas anthropogenic compounds have been estimated to account for less than $100 \mathrm{TgCyr}^{-1}$ (Hough and Johnson, 1991; Muller, 1992).

Inspection of the mass spectra in Fig. 8 reveals that either or both of $m / z, 43$ and 44 are the most dominant fragments in all cases; contributing up to $20 \%$ each to the to- tal organic signal. As discussed before, $m / z 43$ arises from the $\left(\mathrm{C}_{3} \mathrm{H}_{7}^{+}\right)$fragment of saturated hydrocarbons in trafficdominated environments and/or from the acetyl moiety of carbonyl-containing compounds $\left(\mathrm{CH}_{3} \mathrm{CO}^{+}\right)$(Alfarra et al., 2004), which explains its significant contributions to the mass spectra measured in the traffic-dominated urban environment (panel b) and the biogenic compounds-dominated forest (panel f). On the other hand, mass fragment 44 was observed to be the AMS signature of highly oxidised compounds such as di- and multifunctional carboxylic acids. This finding has been established as a result of direct comparisons of the laboratory-generated AMS and standard NIST reported mass spectra of organic compounds representing various classes, such as alcohols, aldehydes, oxo-aldehydes, ketones, esters, saturated and aromatic hydrocarbons, phenols, PAHs, and hydroxy-, oxo-, mono-, and di-carboxylic acids (Alfarra, 2004). The AMS spectra compared well to the NIST spectra in all cases with subtle differences in fragment intensities. The only exception was found in the oxoand di-carboxylic acid case, where mass fragment 44 dominated the AMS spectra, while it was nearly absent in the NIST data. Mass fragment 44 was also found dominant in a laboratory-generated mass spectrum of fulvic acid (Fig. 8, panel e) a humic-like substance containing poly-carboxylic acid groups. Carboxylic acids and humic-like substances have been widely reported in processed organic particles measured in various locations (Havers et al., 1998; Facchini et al., 1999a; Zappoli et al., 1999; Decesari et al., 2000; Krivacsy et al., 2000, 2001). This appears to be in agreement with the mass spectra measured at the JFJ remote site (panel d) as well as the Canadian rural location (panel c), both dominated by processed aerosol particles.

The urban organic mass spectrum in panel B is characterised by mass fragments $(41,43,55,57,69,71, \ldots)$ representing the ion series $\mathrm{C}_{n} \mathrm{H}_{2 n+1}^{+}$and $\mathrm{C}_{n} \mathrm{H}_{2 n-1}^{+}$and separated by 14 mass units due to loss of $\mathrm{CH}_{2}$. This spectrum is typical of hydrocarbons and has been associated with primary organic particles emitted from combustion sources (mainly traffic-related) in various urban locations (Allan et al., 2003b; Alfarra et al., 2004; Canagaratna et al., 2004). The spectrum also contains a more oxidized organic fraction as indicated by the presence of $m / z 44$. The emission of the primary organic particles prevents a meaningful comparison with the mass 
spectral signature of the photooxidation products of both precursors in the smog chamber.

The photooxidation products of $\alpha$-pinene and 1,3,5-TMB appear to have mass spectral signatures (panels $g$ and a) more similar to that of the particle growth following a nucleation event measured in a location dominated by biogenic emissions (panel $f$ ). In all of the three spectra ( $a, f$ and $g$ ), the contribution of $m / z 43$ to the total organic signal is higher than that of $m / z 44$, implying that the organic aerosols measured in these three systems have more carbonyl-containing compounds (e.g. aldehydes and ketones) than di- and multifunctional carboxylic acids. On the other hand, $m / z 44$ appears to be more dominant in the organic particulates measured at the rural and the remote alpine locations (panels $\mathrm{c}$ and $\mathrm{d}$, respectively) compared to those measured at the smog chamber. This suggests that neither the $\alpha$-pinene nor the 1,3,5-TMB experimental results reproduce the right relative product distribution between carbonyl-containing and multifunctional carboxylic acid species measured at ambient locations influenced by continental aged organic aerosol. These results may well imply that the aerosols produced in the smog chamber represent a "young" SOA that is less aged than the organic aerosols measured at some of ambient locations described here (the contribution of $m / z 44$ to the total organic signal continues to increase as a function of irradiation time in the chamber). These results also indicate that further chemical processing takes place in the aerosol after the initial SOA formation. Other reasons for the differences may be that the photochemical conditions in the chamber, including the $\mathrm{VOC} / \mathrm{NO}_{\mathrm{x}}$ ratio are different from those in the atmosphere; or that the complexity of the precursor pool in the atmosphere gives rise to a change in the product distribution in ambient aerosols compared to the chamber. More work is clearly needed to understand this issue.

Acknowledgements. The AMS was purchased through Natural Environmental Research Council (NERC) research grant GR3/12499 and maintained through the NERC-National Centre for Atmospheric Science (NCAS) University Facility for Atmospheric Measurement (UFAM). Further support was provided by NERC research grant NER/A/S/2003/00541. The PSI chamber facility was supported by the EC project EUROCHAMP (Integration of European Simulation Chambers for Investigating Atmospheric Processes) and the Swiss National Science Foundation. The authors would like to thank J. L. Jimenez for useful comments and discussions.

Edited by: S. Martin

\section{References}

Alfarra, M. R.: Insights into atmospheric organic aerosols using an aerosol mass spectrometer, Thesis, University of Manchester Institute of Science and Technology (UMIST), UK, 2004.

Alfarra, M. R., Coe, H., Allan, J. D., Bower, K. N., Boudries, H., Canagaratna, M. R., Jimenez, J. L., Jayne, J. T., Garforth, A., Li, S.-M., and Worsnop, D. R.: Characterization of urban and rural organic particulate in the Lower Fraser Valley using two Aerodyne aerosol mass spectrometers, Atmos. Environ., 38(34), 5745-5758, 2004.

Allan, J. D., Alfarra, M. R., Bower, K. N., Coe, H., Jayne, J. T., Worsnop, D. R., Aalto, P. P., Kulmala, M., Hyötyläinen, T., Cavalli, F., and Laaksonen, A.: Size and composition measurements of background aerosol and new particle growth in a Finnish forest during QUEST 2 using an Aerodyne Aerosol Mass Spectrometer, Atmos. Chem. Phys., 6, 315-327, 2006, http://www.atmos-chem-phys.net/6/315/2006/.

Allan, J. D., Alfarra, M. R., Bower, K. N., Williams, P. I., Gallagher, M. W., Jimenez, J. L., McDonald, A. G., Nemitz, E., Canagaratna, M. R., Jayne, J. T., Coe, H., and Worsnop, D. R.: Quantitative sampling using an Aerodyne aerosol mass spectrometer - 2. Measurements of fine particulate chemical composition in two U.K. cities, J. Geophys. Res.-Atmos., 108(D3), 4091, doi:10.1029/2002JD002359, 2003b.

Allan, J. D., Delia, A. E., Coe, H., Bower, K. N., Alfarra, M. R., Jimenez, J. L., Middlebrook, A. M., Drewnick, F., Onasch, T. B., and Canagaratna, M. R.: A generalised method for the extraction of chemically resolved mass spectra from Aerodyne aerosol mass spectrometer data, J. Aerosol Sci., 35(7), 909-922, 2004.

Allan, J. D., Jimenez, J. L., Williams, P. I., Alfarra, M. R., Bower, K. N., Jayne, J. T., Coe, H., and Worsnop, D. R.: Quantitative sampling using an Aerodyne aerosol mass spectrometer 1. Techniques of data interpretation and error analysis, J. Geophys. Res.-Atmos., 108(D3), 4090, doi:10.1029/2002JD002359, 2003a.

Aschmann, S. M., Atkinson, R., and Arey, J.: Products of reaction of OH radicals with $\alpha$-pinene, J. Geophys. Res., 107(D14), 4191, doi:10.1029/2002JD002358, 2002.

Aschmann, S. M., Reissell, A., Atkinson, R., and Arey, J.: Products of the gas phase reactions of the $\mathrm{OH}$ radical with alpha- and beta-pinene in the presence of NO, J. Geophys. Res., 103(D19), 25 553, doi:10.1029/98JD01676, 1998.

Bahreini, R., Keywood, M. D., Ng, N. L., Varutbangkul, V., Gao, S., Flagan, R. C., Seinfeld, J. H., Worsnop, D. R., and Jimenez, J. L.: Measurements of secondary organic aerosol from oxidation of cycloalkenes, Terpenes, and $m$-xylene using an aerodyne aerosol mass spectrometer, Environ. Sci. Technol., 39(15), 5674-5688, 2005.

Baltensperger, U., Kalberer, M., Dommen, J., Paulsen, D., Alfarra, M. R., Coe, H., Fisseha, R., Gascho, A., Gysel, M., Nyeki, S., Sax, M., Steinbacher, M., Prevot, A. S. H., Sjögren, S., Weingartner, E., and Zenobi, R.: Secondary organic aerosols from anthropogenic and biogenic precursors, Faraday Discuss., 130, 265-278, 2005.

Boudries, H., Canagaratna, M. R., Jayne, J. T., Alfarra, M. R., Allan, J. D., Bower, K. N., Coe, H., Pryor, S. C., Jimenez, J. L., Brook, J. R., Li, S., and Worsnop, D. R.: Chemical and Physical Processes Controlling the Distribution of Aerosol in the Lower Fraser Valley, Canada, during the PACIFIC 2001 Filed Cam- 
paign, Atmos. Environ., 38(34), 5759-5774, 2004.

Calvert, J. G., Atkinson, R., Becker, K. H., Kamens, R. M., Seinfeld, J. H., Wallington, T. H., and Yarwood, G.: The Mechanisms of Atmospheric Oxidation of the Aromatic Hydrocarbons, Oxford University Press, 2002.

Canagaratna, M. R., Jayne, J. T., Ghertner, D. A., Herndon, S., Shi, Q., Jimenez, J. L., Silva, P. J., Williams, P., Lanni, T., Drewnick, F., Demerjian, K. L., Kolb, C. E., and Worsnop, D. R.: Chase studies of particulate emissions from in-use New York city vehicles, Aerosol Sci. Technol., 38, 555-573, 2004.

Charlson, R. J., Schwartz, S. E., Hales, J. M., Cess, R. D., Coakley, J. A., Hansen, J. E., and Hofmann, D. J.: Climate forcing by anthropogenic aerosols, Sci., 255(5043), 423-430, 1992.

Cocker, D. R., Mader, B. T., Kalberer, M., Flagan, R. C., and Seinfeld, J. H.: The effect of water on gas-particle partitioning of secondary organic aerosol: II. m-xylene and 1,3,5-trimethylbenzene photooxidation systems, Atmos. Environ., 35, 6073-6085, 2001.

Cruz, C. N. and Pandis, S. N.: A study of the ability of pure secondary organic aerosol to act as cloud condensation nuclei, Atmos. Environ., 31(15), 2205-2214, 1997.

DeCarlo, P., Slowik, J. G., Worsnop, D. R., Davidovits, P., and Jimenez, J. L.: Particle morphology and density characterization by combined mobility and aerodynamic diameter measurements. Part 1: Theory., Aerosol Sci. Technol., 38, 1185-1205, 2004.

Decesari, S., Facchini, M. C., Fuzzi, S., and Tagliavini, E.: Characterization of water-soluble organic compounds in atmospheric aerosol: A new approach, J. Geophys. Res.-Atmos., 105(D1), 1481-1489, 2000.

Dockery, D. W., Pope, C. A., Xu, X. P., Spengler, J. D., Ware, J. H., Fay, M. E., Ferris, B. G., and Speizer, F. E.: An association between air-pollution and mortality in 6 United States cities, New England Journal of Medicine, 329(24), 1753-1759, 1993.

Facchini, M. C., Fuzzi, S., Zappoli, S., Andracchio, A., Gelencser, A., Kiss, G., Krivacsy, Z., Meszaros, E., Hansson, H.-C., Alsberg, T., and Zebuhr, Y.: Partitioning of the organic aerosol component between fog droplets and interstitial air, J. Geophys. Res., 104, 26 821-26 832, 1999a.

Facchini, M. C., Mircea, M., Fuzzi, S., and Charlson, R. J.: Cloud albedo enhancement by surface-active organic solutes in growing droplets, Nature, 401(6750), 257-259, 1999b.

Fehsenfeld, F., Calvert, J., Fall, R., Goldan, P., Guenther, A. B., Hewitt, C. N., Lamb, B., Liu, S., Trainer, M., Westberg, H., and Zimmerman, P.: Emissions of volatile organic compounds from vegetation and the implications for atmospheric chemistry, Global Biogeochem. Cycles, 6, 389-430, 1992.

Finlayson-Pitts, B. J. and Pitts, J. N.: Chemistry of the Upper and Lower Atmosphere: Theory, Experiments and Applications, Academic Press, San Diego, Calif., London, 2000.

Fisseha, R., Dommen, J., Sax, M., Paulsen, D., Kalberer, M., Maurer, R., Höfler, F., and Baltensperger, U.: Identification of organic acids in secondary organic aerosol from chamber experiments, Anal. Chem., 76(22), 6535-6540, 2004.

Forstner, H. J. L., Flagan, R. C., and Seinfeld, J. H.: Secondary organic aerosol from the photoxidation of aromatic hydrocarbons: molecular composition, Environ. Sci. Technol., 31, 1345-1358, 1997.

Gao, S., Keywood, M., Ng, N. L., Surratt, J., Varutbangkul, V., Bahreini, R., Flagan, R. C., and Seinfeld, J. H.: Low-molecular weight and oligomeric components in secondary organic aerosol from the ozonolysis of cycloalkenes and alpha-pinene, J. Phys. Chem., 108, 10 147-10 164, 2004a.

Gao, S., Ng, N. L., Keywood, M., Varutbangkul, V., Bahreini, R., Nenes, A., He, J., Yoo, K. Y., Beauchamp, J. L., Hodyss, R. P., Flagan, R. C., and Seinfeld, J. H.: Particle phase acidity and oligomer formation in secondary organic aerosol, Environ. Sci. Technol., 38, 6582-6589, 2004b.

Glasius, M., Lahaniati, M., Calogirou, A., Bella, D. D., Jensen, N. R., Hjorth, J., Kotzias, D., and Larsen, B. R.: Carboxylic acids in secondary aerosol from oxidation of cyclic monoterpenes by ozone, Environ. Sci. Technol., 34, 1001-1010, 2000.

Griffin, R. J., Cocker, D. R., Flagan, R. C., and Seinfeld, J. H.: Organic aerosol formation from the oxidation of biogenic hydrocarbons, J. Geophys. Res., 104(D3), 3555-3567, 1999.

Griffin, R. J., Dabdub, D., and Seinfeld, J. H.: Secondary organic aerosol, 1. Atmospheric chemical mechanism for production of molecular constituents, J. Geophys. Res., 107(D17), 4332, doi:10.1029/2001JD000541, 2002.

Gross, D. S., Gälli, M. E., Kalberer, M., Prevot, A. S. H., Dommen, J., Alfarra, M. R., Duplissy, J., Gaeggeler, K., Gascho, A., Metzger, A., and Baltensperger, U.: Real time measurement of oligomeric species in secondary organic aerosol with the aerosol time-of-flight mass spectrometer, Anal. Chem., 78(7), 2130-2137, 2006.

Guenther, A., Hewitt, C. N., Erickson, D., Fall, R., Geron, C., Graedel, T., Harley, P., Klinger, L., Lerdau, M., McKay, W. A., Pierce, T., Scholes, B., Steinbrecher, R., Tallamraju, R., Taylor, J., and Zimmerman, P.: A global model of natural volatile organic compound emissions, J. Geophys. Res., 100, 8873-8892, 1995.

Havers, N., Burba, P., Lambert, J., and Klockow, D.: Spectroscopic characterisation of humic-like substances in airborne particulate matter, J. Atmos. Chem., 29, 45-54, 1998.

Hoffmann, T., Odum, J. R., Bowman, F., Collins, D., Klowckow, D., Flagan, R. C., and H., S. J.: Formation of organic aerosols from the oxidation of biogenic hydrocarbons, J. Atmos. Chem., 26, 189-222, 1997.

Hough, A. M. and Johnson, C. E.: Modelling the role of nitrogen oxides, hydrocarbons and carbon monoxide in the global formation of tropospheric oxidants, Atmos. Environ., 25A, 1819-1835, 1991.

Huffman, J. A., Jayne, J. T., Drewnick, F., Aiken, A. C., Onasch, T., Worsnop, D. R., and Jimenez, J. L.: Design, modeling, optimization, and experimental tests of a particle beam width probe for the Aerodyne aerosol mass spectrometer, Aerosol Sci. Technol., 39(12), 1143-1163, 2005.

Inuma, Y., Boge, O., Gnauk, T., and Herrmann, H.: Aerosolchamber study of the $\alpha$-pinene/O3 reaction: influence of particle acidity on aerosol yields and products, Atmos. Environ., 38(5), 761-773, 2004.

Jang, M. and Kamens, R. M.: Characterization of secondary aerosol from the photooxidation of toluene in the presence of $\mathrm{NO}_{\mathrm{x}}$ and 1-propene, Environ. Sci. Technol., 35, 3626-3639, 2001.

Jang, M. S., Carroll, B., Chandramouli, B., and Kamens, R. M.: Particle growth by acid-catalyzed heterogeneous reactions of organic carbonyls on preexisting aerosols, Environ. Sci. Technol., 37(17), 3828-3837, 2003.

Jaoui, M. and Kamens, R. M.: Gaseous and particulate oxidation products analysis of a mixture of $\alpha$-pinene $+\beta$-pinene $/ \mathrm{O}_{3} /$ air in 
the absence of light and $\alpha$-pinene $+\beta$-pinene/ $/ \mathrm{NO}_{\mathrm{x}} /$ air in the presence of natural sunlight, J. Atmos. Chem., 44, 259-297, 2003.

Jayne, J. T., Leard, D. C., Zhang, X. F., Davidovits, P., Smith, K. A., Kolb, C. E., and Worsnop, D. R.: Development of an aerosol mass spectrometer for size and composition analysis of submicron particles, Aerosol Sci. Technol., 33(1-2), 49-70, 2000.

Jimenez, J. L., Bahreini, R., Cocker, D. R., Zhuang, H., Varutbangkul, V., Flagan, R. C., Seinfeld, J. H., O’Dowd, C. D., and Hoffmann, T.: New particle formation from photooxidation of diiodomethane $\left(\mathrm{CH}_{2} \mathrm{I}_{2}\right)$, J. Geophys. Res.-Atmos., 108(D10), 4318, doi:10.1029/2005JD002452, $2003 \mathrm{a}$.

Jimenez, J. L., Jayne, J. T., Shi, Q., Kolb, C. E., Worsnop, D. R., Yourshaw, I., Seinfeld, J. H., Flagan, R. C., Zhang, X., Smith, K. A., Morris, J. W., and Davidovits, P.: Ambient aerosol sampling using the Aerodyne aerosol mass spectrometer, J. Geophys. Res.Atmos., 108(D7), 8425, doi:10.1029/2001JD001213, 2003b.

Kalberer, M., Paulsen, D., Sax, M., Steinbacher, M., Dommen, J., Prevot, A. S. H., Fisseha, R., Weingartner, E., Frankevich, V., Zenobi, R., and Baltensperger, U.: Identification of polymers as major components of atmospheric organic aerosols, Science, 303, 1659-1662, 2004.

Kamens, R., Jang, M., Chien, C., and Leach, K.: Aerosol formation from the reaction of $\alpha$-pinene and ozone using a gas-phase kinetics-aerosol partitioning model, Environ. Sci. Technol., 33, 1430-1438, 1999.

Kamens, R. M. and Jaoui, M.: Modeling aerosol formaiton from $\alpha$ pinene $+\mathrm{NO}_{\mathrm{x}}$ in the presence of natural sunlight using gas-phase kinetics and gas-particle partitioning theory, Environ. Sci. Technol., 35, 1394-1405, 2001.

Kleindienst, T. E., Conver, T. S., McIver, C. D., and Edney, E. O.: Determination of secondary organic aerosol products from the photooxidation of toluene and their implications in ambient PM2.5, J. Atmos. Chem., 47, 79-100, 2004.

Kleindienst, T. E., Smith, D. F., Li, W., Edney, E. O., Driscoll, D. J., Speer, R. E., and Weathers, W. S.: Secondary organic aerosol formation from the oxidation of aromatic hydrocarbons in the presence of dry submicron ammonium sulphate aerosol, Atmos. Environ., 33, 3669-3681, 1999.

Krivacsy, Z., Hoffer, A., Sarvari, Z., Temesi, D., Baltensperger, U., Nyeki, S., Weingartner, E., Kleefeld, S., and Jennings, S. G.: Role of organic and black carbon in the chemical composition of atmospheric aerosol at European background sites, Atmos. Environ., 35(36), 6231-6244, 2001.

Krivacsy, Z., Kiss, G., Varga, B., Galambos, I., Sarvari, Z., Gelencser, A., Molnar, A., Fuzzi, S., Facchini, M. C., and Zappoli, S.: Study of humic-like substances in fog and interstitial aerosol by size-exclusion chromatography and capillary electrophoresis, Atmos. Environ., 34(25), 4273-4281, 2000.

Kroll, J. H., Nga, N. L., Murphy, S. M., Varutbangkul, V., Flagan, R. C., and Seinfeld, J. H.: Chamber Studies of Secondary Organic Aerosol Growth by Reactive Uptake of Simple Carbonyl Compounds, J. Geophys. Res., 110, D23207, doi:10.1029/2005JD006004, 2005.

Larsen, B. R., Bella, D. D., Glasius, M., Winterhalter, R., Jensen, N. R., and Hjorth, J.: Gas-phase OH oxidation of monoterpenes: Gaseous and particulate products, J. Atmos. Chem., 38, 231-276, 2001.

Liggio, J., Li, S. M., and McLaren, R.: Heterogeneous reactions of glyoxal on particulate matter: identification of acetals and sulfate esters, Environ. Sci. Technol., 39(6), 1532-1541, 2005.

Liu, P., Ziemann, P. J., Kittelson, D. B., and McMurry, P. H.: Generating particle beams of controlled dimensions and divergence: I. Theory of particle motion in aerodynamic lenses and nozzle expansions, Aerosol Sci. Technol., 22(3), 293-313, 1995a.

Liu, P., Ziemann, P. J., Kittelson, D. B., and McMurry, P. H.: Generating particle beams of controlled dimensions and divergence: II. Experimental evaluation of particle motion in aerodynamic lenses and nozzle expansions, Aerosol Sci. Technol., 22(3), 314 324, 1995b.

Macias, E. S., Zwicker, J. O., Ouimette, J. R., Hering, S. V., Friedlander, S. K., Cahill, T. A., Kuhlmey, G. A., and Richards, L. W.: Regional haze case studies in the Southwestern U.S. - I. Aerosol chemical composition, Atmos. Environ., 15, 1971-1986, 1981.

McLafferty, F. W. and Turecek, F.: Interpretation of mass spectra, Fourth Edition, University Science Books, 1993.

Muller, J. F.: Geographical distribution and seasonal variation of surface emissions and deposition velocities of atmospheric trace gases, J. Geophys. Res., 97, 3787-3804, 1992.

Novakov, T. and Penner, J. E.: Large contribution of organic aerosols to cloud-condensation nuclei concentrations, Nature, 365, 323-365, 1993.

Noziere, B. and Barnes, I.: Evidence for the formation of a PAN analogue of pinonic structure and investigation of its thermal stability, J. Geophys. Res., 103, 25 587-25 597, 1998.

Noziere, B., Barnes, I., and Becker, K.: Product study and mechanisms of the reactions of $\alpha$-pinene and pinonaldehyde with OH radicals, J. Geophys. Res., 104(D19), 23 645-23 656, doi:1999JD900778, 1999.

Odum, J. R., Hoffmann, T., Bowman, F., Collins, D., Flagan, R. C., and Seinfeld, J. H.: Gas/particle partitioning and secondary organic aerosol yields, Environ. Sci. Technol., 30, 2580-2585, 1996.

Odum, J. R., Jungkamp, T. P. W., Griffin, R. J., Flagan, R. C., and Seinfeld, J. H.: The atmospheric aerosol-forming potential of whole gasoline vapor, Sci., 276, 96-99, 1997.

Pankow, J. F.: An absorption model of the gas/aerosol partitioning involved in the formation of secondary organic aerosol, Atmos. Environ., 28, 189-194, 1994a.

Pankow, J. F.: An absorption model of the gas/aerosol partitioning of organic compounds in the atmosphere, Atmos. Environ., 28, 185-188, 1994b.

Paulsen, D., Dommen, J., Kalberer, M., Prévôt, A. S. H., Richter, R., Sax, M., Steinbacher, M., Weingartner, E., and Baltensperger, U.: Secondary organic aerosol formation by irradiation of $1,3,5$ trimethylbenzene- $\mathrm{NO}_{\mathrm{x}}-\mathrm{H}_{2} \mathrm{O}$ in a new reaction chamber for atmospheric chemistry and physics, Environ. Sci. Technol., 39, 2668-2678, 2005.

Paulsen, D., Weingartner, E., Alfarra, M. R., and Baltensperger, U.: Volatility measurements of photochemically and nebulizergenerated organic aerosol particles, J. Aerosol Sci., J. Aerosol Sci., 37(9), 1025-1051, 2006.

Seinfeld, J. H. and Pandis, S. N.: Atmospheric Chemistry and Physics: from Air Pollution to Climate Change, John Wiley \& Sons, New York, Chichester, 1998.

Tobias, H. J. and Ziemann, P. J.: Thermal desorption mass spectrometric analysis of organic aerosol formed from reactions of 1-tetradecene and $\mathrm{O} 3$ in the presence of alcohols and carboxylic acids, Environ. Sci. Technol., 34(11), 2105-2115, 2000. 
Tolocka, M. P., Jang, M., Ginter, J. M., Cox, F. J., Kamens, R. M., and Johnston, M. V.: Formation of oligomers in secondary organic aerosol, Environ. Sci. Technol., 38, 1428-1434, 2004.

Vasconcelos, L. A., Macias, E. S., and White, W. H.: Aerosol composition as a function of haze and humidity levels in the southwestern US, Atmos. Environ., 28, 3679-3691, 1994.

Went, F. W.: Blue haze in the atmosphere, Nature, 187, 641-643, 1960.

Zappoli, S., Andracchio, A., Fuzzi, S., Facchini, M. C., Gelencser, A., Kiss, G., Krivacsy, Z., Molnar, A., Meszaros, E., and Hansson, H.-C.: Inorganic, organic and macromolecular components of fine aerosol in different areas of Europe in relation to their water solubility, Atmos. Environ., 33(17), 2733-2743, 1999.
Zhang, Q., Stanier, C. O., Canagaratna, M. C., Jayne, J. T., Worsnop, D. R., Pandis, S. N., and Jimenez, J. L.: Insights into the chemistry of nucleation bursts and new particle growth events in Pittsburgh based on aerosol mass spectrometry, Environ. Sci. Technol., 38, 4797-4809, 2004.

Zhang, X. F., Smith, K. A., Worsnop, D. R., Jimenez, J., Jayne, J. T., and Kolb, C. E.: A numerical characterization of particle beam collimation by an aerodynamic lens-nozzle system: Part I. An individual lens or nozzle, Aerosol Sci.Technol., 36(5), 617-631, 2002.

Zhang, X. F., Smith, K. A., Worsnop, D. R., Jimenez, J. L., Jayne, J. T., Kolb, C. E., Morris, J., and Davidovits, P.: Numerical characterization of particle beam collimation: Part II. Integrated aerodynamic lens-nozzle system, Aerosol Sci. Technol., 38(6), 619638, 2004. 